\title{
Carboplatin dosing in overweight and obese patients with normal renal function, does weight matter?
}

\author{
Corine Ekhart $\cdot$ Sjoerd Rodenhuis • \\ Jan H. M. Schellens · Jos H. Beijnen • \\ Alwin D. R. Huitema
}

Received: 17 July 2008/Accepted: 10 October 2008/Published online: 7 November 2008

(C) The Author(s) 2008. This article is published with open access at Springerlink.com

\begin{abstract}
Purpose The purpose of this study was to determine the potential utility of alternative weight descriptors in the Cockcroft-Gault equation to more accurately predict carboplatin clearance in underweight, normal weight, overweight and obese patients.

Methods Clearance values obtained from individual fits using NONMEM were compared to predicted carboplatin clearances calculated using the modified Calvert formula in which creatinine clearance was calculated with the Cockcroft-Gault equation using diverse weight descriptors.

Results This study indicated that lean body mass was the best weight descriptor in underweight and normal weight patients, while adjusted ideal body weight was the best weight descriptor in overweight and obese patients. However, a flat dose based on the population carboplatin clearance performed better in all weight categories than the use of the Cockcroft-Gault equation with diverse weight descriptors.

Conclusion These results suggest that in overweight and obese patients, with a normal renal function, a flat
\end{abstract}

C. Ekhart $(\varangle)$ J. H. Beijnen · A. D. R. Huitema

Department of Pharmacy and Pharmacology, Slotervaart

Hospital, The Netherlands Cancer Institute, Louwesweg 6,

1066 EC Amsterdam, The Netherlands

e-mail: Corine.Ekhart@slz.nl

S. Rodenhuis · J. H. M. Schellens

Department of Medical Oncology, Antoni van Leeuwenhoek

Hospital, The Netherlands Cancer Institute, Amsterdam,

The Netherlands

J. H. M. Schellens - J. H. Beijnen

Section of Drug Toxicology, Department of Biomedical

Analysis, Faculty of Pharmaceutical Sciences,

Utrecht University, Utrecht, The Netherlands carboplatin dose should be administered, based on the population carboplatin clearance $(8.38 \mathrm{l} / \mathrm{h}=140 \mathrm{~mL} / \mathrm{min})$. Thus, in case an AUC of $5 \mathrm{mg} \mathrm{min} / \mathrm{mL}$ is desired, the appropriate dose for carboplatin would be $5 \times 140=$ $700 \mathrm{mg}$.

Keywords Carboplatin - Dose adaptation - Body weight . Pharmacokinetics

\section{Introduction}

Carboplatin is a widely used platinum compound in combination chemotherapy regimens for the treatment of a number of malignancies. Carboplatin is mainly eliminated by the kidneys, as indicated by the fact that about $65 \%$ of the administered dose is excreted into the urine within the first $24 \mathrm{~h}$ after administration [1]. A small fraction of the drug binds irreversibly to plasma proteins and the free, ultrafilterable platinum fraction is considered pharmacologically active [2]. Carboplatin clearance appears to be directly related to the glomerular filtration rate (GFR) and several dosing formulae have been suggested to calculate an a priori carboplatin dose based upon renal function. The Calvert formula $[$ dose $=$ target $\mathrm{AUC} \times(\mathrm{GFR}+25)]$ is the most widely used formula. It does, however, have limitations in clinical practice. Clearance of chromium 51ethylenediaminetetraacetic acid was used for the determination of the GFR [3]. This method is costly, involves a radioactive compound and is not readily available in most treatment centres. Therefore, for clinical purposes, GFR is usually estimated from a single measurement of serum creatinine by renal function equations that include age, weight and sex to account for interindividual differences in muscle mass and the consequent differences in creatinine 
generation. The GFR is often substituted by the creatinine clearance $\left(\mathrm{CL}_{\mathrm{cr}}\right)$ calculated using the Cockcroft-Gault equation [4]:

$$
\begin{aligned}
\mathrm{CL}_{\mathrm{cr}}= & 1.23 \times(140-\text { age }) \times \text { weight } \\
& \times 0.85(\text { if female }) / \text { serum creatinine. }
\end{aligned}
$$

In a previous study, with approximately the same dataset as this study, no relation between creatinine clearance estimators (using the Cockcroft-Gault, Jelliffe and Wright formulae) and carboplatin clearance was found [5]. However, this study did not take diverse weight measures into account. In the Cockcroft-Gault equation body weight is one of the variables required to calculate the creatinine clearance. This can lead to bias in overweight and obese patients, since in obesity a higher body weight is mainly due to a higher fat mass, whereas the factor body weight in the equation is assumed to reflect muscle mass.

Indeed, it has been shown that creatinine clearance estimates in the obese are inaccurate using either actual body weight (overprediction) or ideal body weight (underprediction) [6]. Clinical evidence showed that using actual body weight in the Cockcroft-Gault equation led to an overprediction of the creatinine clearance and, by applying a modified Calvert formula with creatinine clearance as GFR to calculate the dose, produced a higher than expected carboplatin area under the concentrationtime curve [7, 8]. Calculation of carboplatin clearance may be more accurate by using other weight descriptors such as fat-free mass or adjusted ideal body weight $[8,9]$. Since the Cockcroft-Gault equation is widely used in clinical practice for creatinine clearance calculation to be applied in the Calvert formula, there is a risk of significant overdosing of carboplatin in overweight and obese patients. The purpose of this study was to determine which weight descriptor could best be used in the Cockcroft-Gault equation to accurately predict the carboplatin clearance in overweight and obese patients.

\section{Patients and methods}

\section{Patients}

Pharmacokinetic data of ultrafilterable platinum were available of 240 patients (380 courses, in total 4,478 samples). The data were obtained from several previously published studies in which patients received carboplatin both in high-dose as well as in conventionaldose regimens in combination with other chemotherapeutic agents [10-14]. All protocols were approved by the Committee of Medical Ethics of the Netherlands
Cancer Institute and written informed consent was obtained from all patients.

Sampling and analyses

The number and time-points of samples withdrawn in each study protocol are depicted in Table 1. In all studies, plasma ultrafiltrate was prepared immediately after blood sampling, using the Amicon micropartition system with an YMT-14 membrane (30 kD, Millipore Corporation, Bedford, MA, USA). A volume of $0.5 \mathrm{~mL}$ plasma was transferred in the micropartition system and centrifuged at $2,500 \mathrm{~g}$ for $20 \mathrm{~min}$. Ultrafiltrate was stored at $-20^{\circ} \mathrm{C}$ until analysis. Analysis of platinum in ultrafiltrate was performed using flameless atomic absorption spectrometry as previously described [15]. Accuracy and day-to-day imprecision of this method were 93.9-103.3 and 1.5$10.2 \%$, respectively.

Pretreatment serum creatinine levels were estimated by the kinetic Jaffé method (Hitachi systems, Roche Diagnostics, The Netherlands) in three studies [12-14] and in the first 32 patients of one study [11], while in the remaining patients $[10,11]$ the compensated Jaffé method was used. To correct for the different methods used, the serum creatinine values obtained with the kinetic Jaffé method were retrospectively adjusted by subtracting $26 \mu \mathrm{M}$ from the initial values as proposed and validated by the manufacturer (Roche Diagnostics, The Netherlands).

\section{Pharmacokinetics and data analysis}

For the evaluation of the bias and imprecision of the diverse weight descriptors in the Cockcroft-Gault equation in predicting individual carboplatin clearances, individual fits of the observed carboplatin-time data were used. Individual fits were obtained by fitting a two-compartment model to the carboplatin-time data using the non-linear mixed effect modelling program NONMEM (version VI) (GloboMax LLC, Hanover, USA) [16]. Clearance-values obtained from these individual fits were compared to the predicted carboplatin clearances. Predicted carboplatin clearances $\left(\mathrm{CL}_{\text {est }}\right)$ were calculated using the modified Calvert formula $\left(\mathrm{CL}_{\text {carbo }}=\mathrm{CL}_{\mathrm{cr}}+\right.$ $25)$, in which the creatinine clearance was calculated with the Cockcroft-Gault equation using diverse weight descriptors (Table 3). Bias and imprecision of the diverse weight descriptors were evaluated using the percentage mean prediction error (MPE\%) and the percentage mean absolute prediction error (MAPE\%). The MPE\% is a measure of bias and MAPE\% is a measure of imprecision and were defined as: 
Table 1 Baseline patient characteristics

Number

Median (range)

Patient characteristics

Female/male

$161 / 79$

Age (years)

47 (16-75)

BSA $\left(\mathrm{m}^{2}\right)$

$1.81(1.49-2.94)$

BMI $\left(\mathrm{kg} / \mathrm{m}^{2}\right)$

$24(16-46)$

Weight $(\mathrm{kg})$

70 (46-170)

Height $(\mathrm{cm})$

$171(153-210)$

Protocol

Non-small cell lung cancer [10]

2-6 $\times$ PC $^{\mathrm{a}}$ (dose carboplatin AUC $6 \mathrm{mg} \mathrm{min} / \mathrm{mL}$ administered in $30 \mathrm{~min}$ )

Non-small cell lung cancer [13, 14]

PC (dose carboplatin $300-400 \mathrm{mg} / \mathrm{m}^{2}$ per $30 \mathrm{~min}$ )

Ovarian cancer $[12,14]$

PC (dose carboplatin $300-600 \mathrm{mg} / \mathrm{m}^{2}$ per $30 \mathrm{~min}$ )

High-risk primary breast cancer [11]

CTC $^{\text {b }}$ (dose carboplatin $400 \mathrm{mg} / \mathrm{m}^{2}$ per day or AUC $20 \mathrm{mg} \mathrm{min} / \mathrm{mL}$ administered in $1 \mathrm{~h}$ for 4 days)

Metastatic breast cancer [11] (and additional pat's) tCTC (dose carboplatin $267 \mathrm{mg} / \mathrm{m}^{2}$ per day or AUC $13.3 \mathrm{mg}$ min per $\mathrm{mL}$ administered in $1 \mathrm{~h}$ for 4 days)

Refractory germ cell cancer [11] (and additional pat's)

CTC (dose carboplatin $400 \mathrm{mg} / \mathrm{m}^{2} /$ day or AUC $20 \mathrm{mg} \mathrm{min} / \mathrm{mL}$ administered in $1 \mathrm{~h}$ for 4 days)

Refractory germ cell cancer [11] (and additional pat's)

tCTC (dose carboplatin $267 \mathrm{mg} / \mathrm{m}^{2}$ per day or AUC $13.3 \mathrm{mg} \mathrm{min} / \mathrm{mL}$ administered in $1 \mathrm{~h}$ for 4 days)

Metastatic ovarian cancer [11]

tCTC (dose carboplatin $267 \mathrm{mg} / \mathrm{m}^{2}$ per day or AUC $13.3 \mathrm{mg} \mathrm{min} / \mathrm{mL}$ administered in $1 \mathrm{~h}$ for 4 days)

Epithelial breast cancer

miniCTC $^{\mathrm{c}}$ (dose carboplatin $400 \mathrm{mg} / \mathrm{m}^{2}$ per day or AUC $10 \mathrm{mg} \mathrm{min} / \mathrm{mL}$ administered in $1 \mathrm{~h}$ for 2 days)

21 (21 courses)

Four plasma samples per patient per course

$t=0.5,4.5,8.5,23.5 \mathrm{~h}$

58 (95 courses)

Six to ten plasma samples per patient per course

$t=0.5,0.75,1,1.5,2.5,4.5,8.5,12.5,24.5,48.5 \mathrm{~h}$

25 ( 25 courses)

8-12 plasma samples per patient per course

$t=0.5,0.75,1,1.5,2.5,4.5,8.5,12.5,18.5,24.5,48.5 \mathrm{~h}$

44 (44 courses)

15-20 plasma samples per patient per course

$t=0.5,0.75,1,1.5,2.5,4.5,8.5,12.5,18.5,24.5,48.5 \mathrm{~h}$.

Days 1 and 3

47 (113 courses)

15-20 plasma samples per patient per course

$t=0.5,1,1.5,1.75,2,2.5,3.75,5.5,10,24 \mathrm{~h}$.

Days 1 and 3

19 (35 courses)

15-20 plasma samples per patient per course

$t=0.5,1,1.5,1.75,2,2.5,3.75,5.5,10,24 \mathrm{~h}$ days 1 and 3

Five (14 courses)

15-20 plasma samples per patient per course

$t=0.5,1,1.5,1.75,2,2.5,3.75,5.5,10,24$ h days 1 and 3

\section{5 (6 courses)}

15-20 plasma samples per patient per course

$t=0.5,1,1.5,1.75,2,2.5,3.75,5.5,10,24 \mathrm{~h}$.

Days 1 and 3

16 (27 courses)

12-16 plasma samples per patient per course

$t=0.5,1,1.5,2,2.5,3.75,5.5,10 \mathrm{~h}$ days 1 and 2

$57(18-124)$

$126(55-451)$

Serum creatinine $(\mu \mathrm{M})$

$42(18-52)$

Cockcroft-Gault formula (mL/min) [4]

Albumin (g/L)

a $P C$ Paclitaxel and carboplatin

b (t)CTC, high-dose cyclophosphamide ( $1 \mathrm{~h}$ infusion), carboplatin ( $1 \mathrm{~h}$ infusion) and thiotepa $(2 \times 0.5 \mathrm{~h}$ infusion) every day during 4 days

c miniCTC, day 1 cyclophosphamide ( $1 \mathrm{~h}$ infusion) and carboplatin ( $1 \mathrm{~h}$ infusion), day 2 thiotepa ( $1 \mathrm{~h}$ infusion) and carboplatin ( $1 \mathrm{~h}$ infusion) 
$\mathrm{MPE} \%=\sum(\mathrm{pe}) / N \times 100 \%$

$\mathrm{MAPE} \%=\sum|\mathrm{pe}| / N \times 100 \%$

with pe $=$ prediction error defined as:

$\left(\mathrm{CL}_{\text {est }}-\mathrm{CL}_{\text {ind }}\right) / \mathrm{CL}_{\text {ind }}$.

In the second part of the analysis, the relation between carboplatin clearance and weight was determined using a population pharmacokinetic model. Pharmacokinetic data of carboplatin (measured as free platinum) were analysed with a population pharmacokinetic model developed using NONMEM (version VI). The first order conditional estimation method (FOCE) with INTERACTION was used after logarithmic data transformation [17]. Pharmacokinetics of carboplatin were described with a twocompartment model with first-order elimination from the central compartment. Interindividual variability (IIV), interoccasion variability (IOV) and residual variability were modelled using a proportional error model.

Correlation of carboplatin clearance with the diverse weight descriptors was investigated by estimating the allometric coefficient for carboplatin clearance, according to the following equation:

$\mathrm{CL}_{i}=\mathrm{CL}_{\text {pop }} \times\left(\mathrm{Wt}_{i} / \mathrm{Wt}\right)^{\mathrm{x}}$

where $\mathrm{CL}_{i}$ is the carboplatin clearance in individual $i$ with weight $\mathrm{Wt}_{i}, \mathrm{CL}_{\text {pop }}$ is the population carboplatin clearance standardized to an individual with median weight $\mathrm{Wt}$ and $\mathrm{x}$ is the allometric coefficient, which marks the exponential decrease or increase in clearance. In this equation, $\mathrm{Wt}_{i}$ and Wt were substituted by several weight descriptors (Table 3). To correct for possible confounding variables, sex was also incorporated in this equation. Significance of incorporation of an allometric coefficient using diverse weight descriptors was evaluated with the objective function value (OFV), which is proportional to negative twice the log likelihood. A difference in OFV of 6.63 between two nested models (corresponding to a $P$ value of 0.01 ) was considered statistically significant.

\section{Results}

Patients

A total of 240 cancer patients were studied of whom 7 (3\%) were defined as underweight [body mass index (BMI) $<18.5 \mathrm{~kg} / \mathrm{m}^{2}$ ], $146(61 \%)$ were defined as normal weight (BMI $\geq 18.5$ to $\left.<25 \mathrm{~kg} / \mathrm{m}^{2}\right), 72(30 \%)$ were defined as overweight (BMI $\geq 25$ to $<30 \mathrm{~kg} / \mathrm{m}^{2}$ ) and $15(6 \%)$ were defined as obese (BMI $\geq 30 \mathrm{~kg} / \mathrm{m}^{2}$ ). Of all patients in the dataset baseline patient characteristics and biochemical
Table 2 Detailed information of the subpopulations

\begin{tabular}{lcll}
\hline Subpopulation & $\begin{array}{l}\text { Female/ } \\
\text { male }\end{array}$ & $\begin{array}{l}\text { Age } \\
\text { Median } \\
\text { (range) }\end{array}$ & $\begin{array}{l}\text { Serum creatinine } \\
(\mu \mathrm{M}) \\
\text { Median (range) }\end{array}$ \\
\hline $\begin{array}{l}\text { Underweight } \\
\mathrm{BMI}<18.5 \mathrm{~kg} / \mathrm{m}^{2}\end{array}$ & $4 / 3$ & $38(16-58)$ & $46(32-62)$ \\
$\begin{array}{l}\text { Normal weight } \\
\mathrm{BMI} \geq 18.5 \text { to }<25 \mathrm{~kg} / \mathrm{m}^{2}\end{array}$ & $97 / 49$ & $46(17-75)$ & $57(18-124)$ \\
$\begin{array}{l}\text { Overweight } \\
\mathrm{BMI} \geq 25 \text { to }<30 \mathrm{~kg} / \mathrm{m}^{2}\end{array}$ & $49 / 23$ & $49(18-74)$ & $62(31-118)$ \\
Obese & $11 / 4$ & $52(28-68)$ & $55(38-87)$ \\
$\mathrm{BMI} \geq 30 \mathrm{~kg} / \mathrm{m}^{2}$ & & & \\
\hline
\end{tabular}

Table 3 Weight descriptors used in the Cockcroft-Gault equation

\begin{tabular}{ll}
\hline Weight descriptor \\
\hline ABW & \\
IBW & $49.9+0.89 \times($ height $(\mathrm{cm})-152.4)$ for men \\
& $45.4+0.89 \times($ height $(\mathrm{cm})-152.4)$ for women \\
AIBW & $\mathrm{IBW}+0.4 \times(\mathrm{ABW}-\mathrm{IBW})$ \\
Benezet [30] & $(\mathrm{IBW}+\mathrm{ABW}) / 2$ \\
FFM & $\mathrm{ABW} \times(1-0.715)+12.1 \times$ height $(\mathrm{m})^{2}$ for men \\
& $\mathrm{ABW} \times(1-0.713)+9.74 \times$ height $(\mathrm{m})^{2}$ for women \\
LBM & $1.1 \times \mathrm{ABW}-0.0128 \times \mathrm{BMI} \times \mathrm{ABW}$ for men \\
& $1.07 \times \mathrm{ABW}-0.0148 \times \mathrm{BMI} \times \mathrm{ABW}$ for women
\end{tabular}

$A B W$ Actual body weight; $I B W$ ideal body weight; $A I B W$ adjusted ideal body weight; $F F M$ fat-free mass according to Salazar and Corcoran [9]; LBM lean body mass; BMI body mass index

parameters were available as summarized in Tables 1 and 2.

Pharmacokinetics and data analysis

Bias and imprecision of estimates of carboplatin clearance based on diverse weight descriptors (Table 3) are listed in Table 4. In underweight patients the use of lean body mass (LBM) in the Cockcroft-Gault equation was the predictor with the lowest bias and imprecision for carboplatin clearance calculated using the modified Calvert formula. The other weight descriptors resulted in overprediction of the carboplatin clearance. In normal weight patients, actual body weight $(\mathrm{ABW})$, ideal body weight (IBW), adjusted ideal body weight (AIBW) and the Benezet equation resulted in overprediction of the carboplatin clearance, while fat-free mass (FFM) and LBM resulted in slight underprediction of the carboplatin clearance. LBM was the weight descriptor that resulted in the lowest bias and imprecision in normal weight patients. In overweight and obese patients, AIBW, the Benezet equation and $\mathrm{ABW}$ 


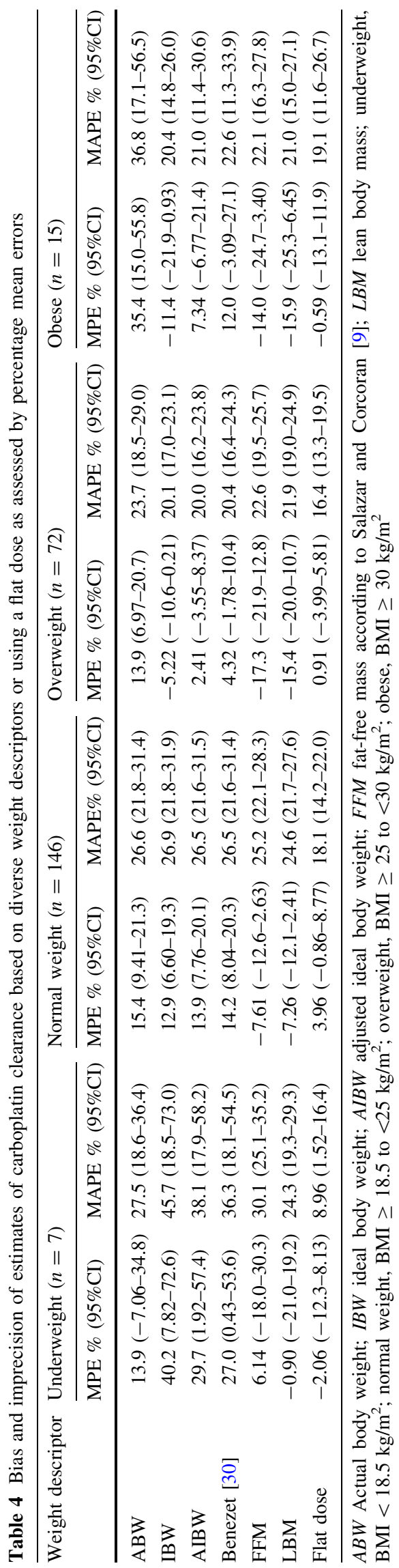

resulted in overprediction of the carboplatin clearance, more so in obese patients compared to overweight patients. IBW resulted in underprediction of the carboplatin clearance also to a greater extent in obese patients compared to overweight patients. LBM and FFM resulted in comparable underpredictions of the carboplatin clearance in overweight and obese patients. The weight descriptor that resulted in the lowest bias and imprecision in overweight and obese patients is AIBW.

Flat dosing based on the population carboplatin clearance resulted in the lowest bias and imprecision in all the weight categories (Table 4), indicating that the relation between carboplatin clearance and weight is much weaker in this patient population than the Cockcroft-Gault equation would imply. This is also shown in Fig. 1 in which the relation between carboplatin clearance and weight of the patients included in this analysis is depicted. Neither actual body weight nor lean body mass showed a strong relation with carboplatin clearance.

Table 5 summarizes the population pharmacokinetic parameters of carboplatin of the basic model, together with the IIV, IOV and residual variability. IIV was estimated for clearance $(\mathrm{CL})$, volume of distribution $(\mathrm{V})$ and the distribution parameters $\mathrm{k}_{12}$ and $\mathrm{k}_{21}$, whereas IOV was estimated for CL and V. All parameters were estimated with an acceptable precision (coefficient of variation 1.41-30.8\%).
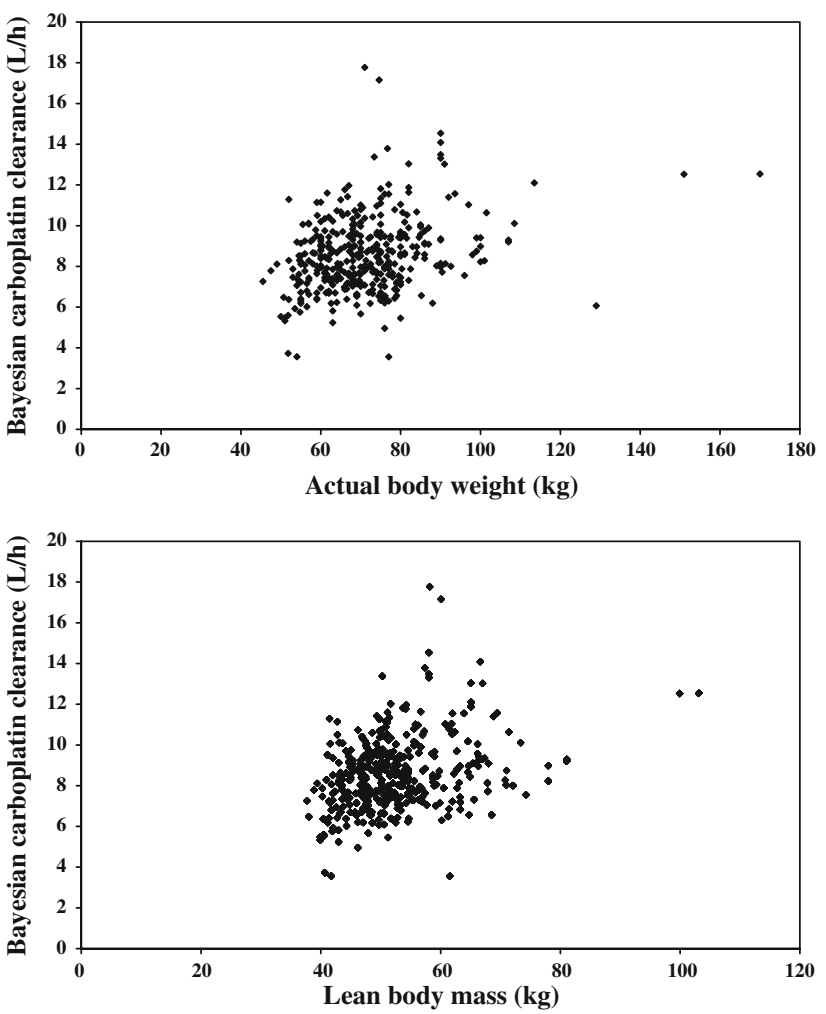

Fig. 1 Relation between carboplatin clearance and weight 


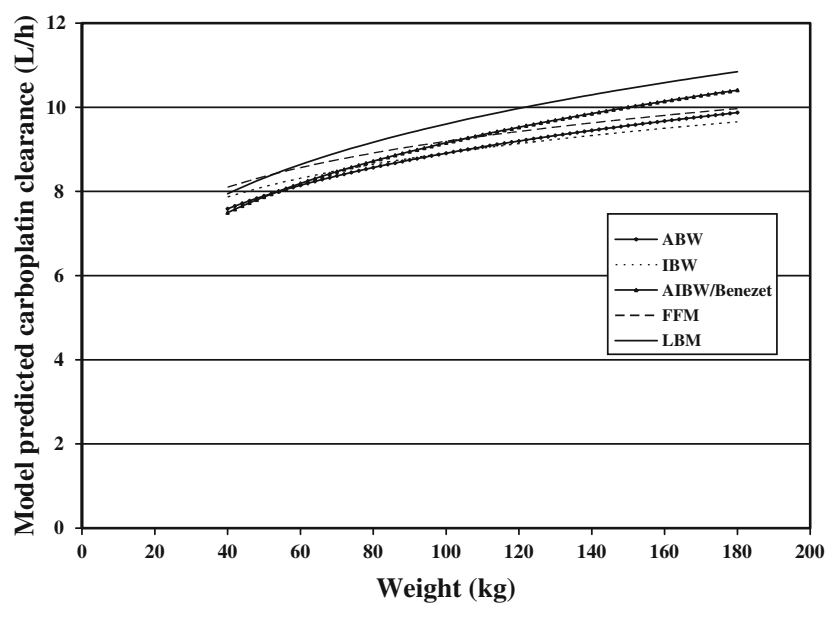

Fig. 2 Model predicted carboplatin clearance versus weight calculated using diverse weight descriptors

Estimation of the allometric coefficient for carboplatin clearance resulted in values ranging from 0.136 to 0.220 for the diverse weight descriptors used (Table 6), indicating that the relation between carboplatin clearance and weight is much weaker than the theoretical allometric coefficient of 0.75. This is also shown graphically in Fig. 2, which shows the relation between weight and carboplatin clearance.

Incorporation of an allometric coefficient did not significantly improve the fit of the model (differences in OFV were less than 6.63) compared to the basic model in which no relation between weight and carboplatin clearance was assumed (Table 6). Nor did it explain a significant part of the interindividual variability in carboplatin clearance. Interindividual variability values of the models incorporating an allometric coefficient (18.5-18.8\%) were all in the same range as the basic model (19.4\%, Table 6).

\section{Discussion}

The proper dosage in overweight and obese individuals is an important subject in clinical practice. With chemotherapeutic agents being dosed by equations incorporating weight, there are concerns about the safety and efficacy in overweight and obese patients [18]. Unfortunately, there is
Table 6 Allometric coefficients for carboplatin clearance using diverse weight descriptors

\begin{tabular}{llll}
\hline Weight descriptor & $\begin{array}{l}\text { Allometric coefficient } \\
(\text { RSE \%) }\end{array}$ & IIV (RSE \%) & $\Delta$ OFV \\
\hline Basic model & & $19.4(8.34)$ & \\
ABW & $0.175(46.2)$ & $18.7(8.52)$ & -6.06 \\
IBW & $0.136(72.9)$ & $18.8(8.91)$ & -2.22 \\
AIBW & $0.218(48.6)$ & $18.5(8.84)$ & -5.03 \\
Benezet [30] & $0.220(46.8)$ & $18.5(8.79)$ & -5.49 \\
FFM & $0.138(72.4)$ & $18.7(8.73)$ & -2.57 \\
LBM & $0.207(46.7)$ & $18.5(8.71)$ & -5.71 \\
\hline
\end{tabular}

$\overline{A B W}$ Actual body weight; $I B W$ ideal body weight; $A I B W$ adjusted ideal body weight; $F F M$ fat-free mass according to Salazar and Corcoran [9]; $L B M$ lean body mass; IIV interindividual variability; $R S E$ relative standard error of estimate; $\triangle O F V$ difference in objective function value of the model incorporating an allometric coefficient compared to the basic model

a lack of data that addresses this issue. In the current study, we sought to identify which weight descriptor should be used in the Cockcroft-Gault equation to accurately predict the carboplatin clearance in overweight and obese patients. For the proper evaluation of this, we included patients who were treated with a variety of chemotherapeutic regimens all including carboplatin. We have demonstrated that adjusted ideal body weight was the best weight descriptor to be used in the Cockcroft-Gault equation in overweight and obese patients, however, the use of weight descriptors in carboplatin dosing did not improve the dosing accuracy compared to flat dosing.

Carboplatin is eliminated through the kidney by glomerular filtration and tubular secretion. There are several discrepancies regarding the influence of obesity on these functions. While some studies have shown an increase in glomerular filtration, measured using creatinine clearance, in obese women as compared to normal weight women [19-21], others have shown decreased glomerular filtration [22] or no significant difference between creatinine clearance in obese versus non-obese individuals [23, 24]. These discrepancies might be due to the difference in extent of obesity and/or associated renal pathology. Tubular secretion is difficult to ascertain, therefore, conclusions regarding tubular secretion are often indirect. An increase
Table 5 Population pharmacokinetic parameters of carboplatin of the basic model

RSE Relative standard error of estimate; $I I V$ interindividual variability; $I O V$ interoccasion variability; $N d$ not determined

\begin{tabular}{llll}
\hline Parameter & Estimate (RSE \%) & \% IIV (RSE \%) & \% IOV (RSE \%) \\
\hline Clearance $(\mathrm{L} / \mathrm{h})$ & $8.38(1.41)$ & $19.4(8.34)$ & $9.14(9.15)$ \\
Volume of distribution $(\mathrm{L})$ & $15.4(1.79)$ & $14.5(11.7)$ & $10.8(14.9)$ \\
Distribution microconstant $\mathrm{k}_{12}\left(\mathrm{~h}^{-1}\right)$ & $0.135(7.85)$ & $48.2(18.9)$ & $\mathrm{Nd}$ \\
Distribution microconstant $\mathrm{k}_{21}\left(\mathrm{~h}^{-1}\right)$ & $0.215(5.91)$ & $43.6(30.8)$ & $\mathrm{Nd}$ \\
Proportional residual error $(\%)$ & $19.7(5.69)$ & & \\
\hline
\end{tabular}


in renal clearance of ciprofloxacin [23], cimetidine [25] and procainamide [26] accompanied by a disproportionate increase in glomerular filtration was seen in obese individuals. Since the renal excretion of these compounds primarily involves glomerular filtration and tubular secretion, these findings support increased tubular secretion in obese individuals.

The Cockcroft-Gault equation has been shown to be biased and inaccurate in some specific patient groups, such as the obese [6, 27]. Van de Ree et al. compared creatinine clearance as calculated by Cockcroft-Gault to creatinine clearance as determined by 24-h urine collection in obese patients and stated that in view of the influence of body weight on the Cockcroft-Gault equation, this equation should not be used to estimate the GFR in patients with extreme obesity [28]. Spinler et al. showed that the Cockcroft-Gault equation using actual body weight tended to overpredict the creatinine clearance in obese patients, while the modified Cockcroft-Gault equation using ideal body weight tended to underpredict creatinine clearance. The use of adjusted ideal body weight may be more accurate [6].

Several studies have evaluated the performance of different weight descriptors in dosing formulae to predict carboplatin exposure. Herrington et al. showed in 19 patients with a BMI $\geq 27 \mathrm{~kg} / \mathrm{m}^{2}$ that the use of the adjusted ideal body weight in the Cockcroft-Gault equation led to less bias and more precision than using actual weight [8]. The use of actual weight in obese patients led to an overestimation of the carboplatin clearance and thus carboplatin exposure. Furthermore, Sparreboom et al showed that when calculating carboplatin doses on the basis of body surface area, either predicted normal weight or the mean of ideal and actual weight, resulted in the best prediction of systemic carboplatin exposure in both obese men and women [29]. Benezet et al. studied the accuracy of the Chatelut formula to predict the carboplatin clearance in a subpopulation of obese patients. They showed that the average of actual body weight and ideal body weight was the best predictor of carboplatin clearance within the formula, integrating body weight, plasma creatinine level, age and sex [30].

In conclusion, these studies showed that neither actual body weight, nor ideal body weight, but an average of both, results in the best prediction of carboplatin clearance in obese patients. These results are in accordance with our study.

In our patient population no strong relation between weight and carboplatin clearance could be demonstrated. This was also seen in a covariate analysis determining the effect of patient-specific factors on carboplatin clearance [31]. It was shown that creatinine clearance determined by the $24 \mathrm{~h}$ urine collection method explained almost two- thirds of the interindividual variability of carboplatin clearance. Height was identified as the second significant covariate of clearance, but accounted for only approximately $10 \%$, while weight was not selected at all.

The extent to which compounds are affected by obesity depends on the lipophilicity of the drug. In general, more lipophilic compounds are affected to a greater extent by obesity than hydrophilic compounds [18]. The excess of adipose tissue in obese patients, has a smaller proportion of water compared to muscle tissue. Carboplatin is hydrophilic in nature and would, therefore, not distribute well through adipose tissue. Thus, carboplatin would not be expected to be influenced by obesity to a great extent. In addition, only lean mass is responsible for production of creatinine. Therefore, weight descriptors that correct for the excess of adipose tissue would be expected to be better predictors of carboplatin clearance than actual body weight.

In a previous study, using approximately the same dataset as this study, we have demonstrated that modification of the Calvert formula by estimating GFR from serum creatinine to calculate an a priori carboplatin dose is not justified in adult patients with normal renal function. No relation between creatinine clearance estimators and carboplatin clearance could be demonstrated in that study [5].

The predominant determinant of carboplatin clearance is the GFR. Although creatinine clearance is widely accepted as a simple measurement of the GFR, it systematically overestimates GFR, owing to creatinine not being solely filtered by the glomerulus but also actively secreted by the proximal tubule. This overestimation of the GFR can also be seen in this study. In normal weight patients ABW, IBW, AIBW or weight calculated with the Benezet equation are all roughly the same. Table 4 shows that the use of the Cockcroft-Gault equation incorporating the aforementioned weight descriptors systematically overestimates carboplatin clearance by around $14 \%$ in normal weight patients, due to the active secretion of creatinine.

The current study showed that when using the Cockcroft-Gault equation to calculate an a priori dose of carboplatin, the use of adjusted ideal body weight results in the best prediction in overweight and obese patients. However, without a clear correlation of weight with carboplatin clearance, the use of the Cockcroft-Gault equation to estimate an a priori dose of carboplatin in overweight or obese patients with adequate renal function should be questioned. Our results suggest that a flat dose (carboplatin dose $=$ target AUC $\times$ carboplatin clearance), based on the population carboplatin clearance $(8.38 \mathrm{l} / \mathrm{h}=140 \mathrm{~mL} /$ min), will result in less bias in overweight and obese patients with adequate renal function. 
Acknowledgments This work was supported with a grant from the Dutch Cancer Society (project NKI 2005-3418).

Open Access This article is distributed under the terms of the Creative Commons Attribution Noncommercial License which permits any noncommercial use, distribution, and reproduction in any medium, provided the original author(s) and source are credited.

\section{References}

1. van der Vijgh WJ (1991) Clinical pharmacokinetics of carboplatin. Clin Pharmacokinet 21(4):242-261

2. Kloft C, Siegert W, Beyer J, Jaehde U (2002) Toxicity of highdose carboplatin: ultrafiltered and not total plasma pharmacokinetics is of clinical relevance. J Clin Pharmacol 42(7):762-773

3. Calvert AH, Newell DR, Gumbrell LA, O'Reilly S, Burnell M, Boxall FE et al (1989) Carboplatin dosage: prospective evaluation of a simple formula based on renal function. J Clin Oncol 7(11):1748-1756

4. Cockcroft DW, Gault MH (1976) Prediction of creatinine clearance from serum creatinine. Nephron 16(1):31-41

5. Ekhart C, de Jonge ME, Huitema AD, Schellens JH, Rodenhuis S, Beijnen JH (2006) Flat dosing of carboplatin is justified in adult patients with normal renal function. Clin Cancer Res 12(21):6502-6508

6. Spinler SA, Nawarskas JJ, Boyce EG, Connors JE, Charland SL, Goldfarb S (1998) Predictive performance of ten equations for estimating creatinine clearance in cardiac patients Iohexol Cooperative Study Group. Ann Pharmacother 32(12):1275-1283

7. de Jonge ME, Mathot RA, van Dam SM, Beijnen JH, Rodenhuis S (2002) Extremely high exposures in an obese patient receiving high-dose cyclophosphamide, thiotepa and carboplatin. Cancer Chemother Pharmacol 50(3):251-255

8. Herrington JD, Tran HT, Riggs MW (2006) Prospective evaluation of carboplatin AUC dosing in patients with a BMI $>$ or $=27$ or cachexia. Cancer Chemother Pharmacol 57(2):241-247

9. Salazar DE, Corcoran GB (1988) Predicting creatinine clearance and renal drug clearance in obese patients from estimated fat-free body mass. Am J Med 84(6):1053-1060

10. De Jonge ME, Van den Bongard HJ, Huitema ADR, Mathot RA, Rosing H, Baas P et al (2004) Bayesian pharmacokinetically guided dosing of paclitaxel in patients with non-small cell lung cancer. Clin Cancer Res 10(7):2237-2244

11. Huitema ADR, Spaander M, Mathot RAA, Tibben MM, Holtkamp MJ, Beijnen JH et al (2002) Relationship between exposure and toxicity in high-dose chemotherapy with cyclophosphamide, thiotepa and carboplatin. Ann Oncol 13(3):374-384

12. Huizing MT, van Warmerdam LJ, Rosing H, Schaefers MC, Lai A, Helmerhorst TJ et al (1997) Phase I and pharmacologic study of the combination paclitaxel and carboplatin as first-line chemotherapy in stage III and IV ovarian cancer. J Clin Oncol 15(5):1953-1964

13. Huizing MT, Giaccone G, van Warmerdam LJ, Rosing H, Bakker PJ, Vermorken JB et al (1997) Pharmacokinetics of paclitaxel and carboplatin in a dose-escalating and dose-sequencing study in patients with non-small-cell lung cancer. The European Cancer Centre. J Clin Oncol 15(1):317-329
14. van Warmerdam LJC, Huizing MT, Giaccone G, Postmus PE, Bokkel Huinink WW, van Zandwijk N et al (1997) Clinical pharmacology of carboplatin administered in combination with paclitaxel. Semin Oncol 24(1 Suppl 2):S2

15. Van Warmerdam LJC, Van Tellingen O, Maes RAA, Beijnen JH (1995) Validated method for the determination of carboplatin in biological fluids by Zeeman atomic absorption spectrometry. Fresenius J Anal Chem 351:777-781

16. Beal SL, Sheiner LB (2006) User's Guides, NONMEM Project Group. University of California at San Francisco, San Francisco 2006. 1998

17. Keene ON (1995) The log transformation is special. Stat Med 14(8):811-819

18. Blouin RA, Warren GW (1999) Pharmacokinetic considerations in obesity. J Pharm Sci 88(1):1-7

19. Davis RL, Quenzer RW, Bozigian HP, Warner CW (1990) Pharmacokinetics of ranitidine in morbidly obese women. DICP 24(11):1040-1043

20. Dionne RE, Bauer LA, Gibson GA, Griffen WO Jr, Blouin RA (1981) Estimating creatinine clearance in morbidity obese patients. Am J Hosp Pharm 38(6):841-844

21. Stokholm KH, Brochner-Mortensen J, Hoilund-Carlsen PF (1980) Increased glomerular filtration rate and adrenocortical function in obese women. Int J Obes 4(1):57-63

22. Ducharme MP, Slaughter RL, Edwards DJ (1994) Vancomycin pharmacokinetics in a patient population: effect of age, gender, and body weight. Ther Drug Monit 16(5):513-518

23. Allard S, Kinzig M, Boivin G, Sorgel F, LeBel M (1993) Intravenous ciprofloxacin disposition in obesity. Clin Pharmacol Ther 54(4):368-373

24. Reiss RA, Haas CE, Karki SD, Gumbiner B, Welle SL, Carson SW (1994) Lithium pharmacokinetics in the obese. Clin Pharmacol Ther 55(4):392-398

25. Bauer LA, Wareing-Tran C, Edwards WA, Raisys V, Ferreri L, Jack $R$ et al (1985) Cimetidine clearance in the obese. Clin Pharmacol Ther 37(4):425-430

26. Christoff PB, Conti DR, Naylor C, Jusko WJ (1983) Procainamide disposition in obesity. Drug Intell Clin Pharm 17(78):516-522

27. Verhave JC, Fesler P, Ribstein J, Du CG, Mimran A (2005) Estimation of renal function in subjects with normal serum creatinine levels: influence of age and body mass index. Am J Kidney Dis 46(2):233-241

28. van de Ree MA, Christiaan G, Huisman MV, van der Vijver JC, Meinders AE (2001) Monitoring renal function in obese patients with type 2 diabetes mellitus in daily practice. Diabetes Nutr Metab 14(2):66-70

29. Sparreboom A, Wolff AC, Mathijssen RH, Chatelut E, Rowinsky EK, Verweij J et al (2007) Evaluation of alternate size descriptors for dose calculation of anticancer drugs in the obese. J Clin Oncol 25(30):4707-4713

30. Benezet S, Guimbaud R, Chatelut E, Chevreau C, Bugat R, Canal $P$ (1997) How to predict carboplatin clearance from standard morphological and biological characteristics in obese patients. Ann Oncol 8(6):607-609

31. Kloft C, Siegert W, Jaehde U (2003) Individualised dosing strategy for high-dose carboplatin in patients with germ cell cancer. Br J Cancer 89(5):787-794 